\title{
Letters
}

\section{Climate change}

\section{Contraction and convergence: myth and reality}

EDITOR-The review of climate change issues in the $B M J$ of 10 June was comprehensive. On grounds of morality, the principle of contraction and convergence is unassailable. ${ }^{1}$ In the real world, it is a pipe dream. It would work only by being enforcible, which implies an international policing authority with real teeth. Can we seriously believe that the United States, China, or Russia would submit to such an authority? Sadly there is no mileage in morality when affluent lifestyles are threatened.

It is right to plead for changes in individual behaviour, but only the de-carbonising of energy at source will make a predictable and sustained impact on carbon dioxide emissions. The only long term route to this goal will be through the adoption of renewable energy technologies on two levels.

Firstly, small scale to micro-generation systems are rapidly approaching market viability. Within five to 10 years, millions of homes could become cost effective mini-power stations linked to a local mini-grid under the umbrella of distributed generation. The Energy Saving Trust estimates that this sector could meet $40 \%$ of UK electricity demand. ${ }^{2}$

Secondly, base load electricity could be provided by gigawatt scale technologies mostly drawing energy from

wind, rivers, and seas. Tidal stream, tidal estuary, tidal impoundment, wave power, and offshore wind could more than match the output of today's nuclear power. ${ }^{3}$ In the short term, "balancing power" to compensate for intermittency would be provided by combined cycle gas power plants. In the longer term, surplus electricity, which is an intrinsic problem with renewables, will be directed to producing hydrogen for grid connected gigawatt scale fuel cells in a symbiotic coupling with high energy density renewables installations. All this will, of course, depend on massive government investment, but so would nuclear energy.

On the demand side, buildings are the biggest carbon culprits. The only effective answer, embracing both new and existing buildings, is the concept of the carbon budget, enforcible by law. This could also be adapted for transport. These have complex implications, perhaps for another time.

Peter F Smith special professor in sustainable energy University of Nottingham, Nottingham NG7 2RD pfsmith@ukonline.co.uk

Competing interests: None declared.

1 Stott R. Healthy response to climate change [with commentary by M Hillman, L Eaton]. BMJ

2 Energy Saving Trust. Potential for microgeneration. Study and Energy Saving Trust. Potential for microg

analysis. Final report. London: EST, 2005. Boyle G, ed. Renewable energy: power for a sustainable futur Oxford: Open University/Oxford University Press,

\section{Summary of responses}

bmj com

Although not everyone agreed that climate change is a suitable topic for a general medical journal, most respondents agreed that its impact on health made it undeniably important and unavoidable. ${ }^{1-4}$ Even so, several respondents severely criticised the lack of a rigorous scientific approach in the articles, as well as their naivety or "preachiness"and a couple challenged why the $B M J$ is sent out in plastic wrappers and not recyclable paper envelopes.

Many agree that, in spite of the gloomy scenario outlined in the articles, doing anything at all is better than nothing-even if it is turning down the water thermostat in hospitals, as one correspondent suggests; turning off unnecessary lights; using bicycles; not buying produce flown in from abroad; restricting the number of people living on the planet by sensible means; and generally developing a much greater carbon awareness. Some remind us that the imbalance between individuals in terms of polluting the environment may not be as big as that between countries, although still substantial.

Hospitals without air conditioning, heating, or car parks are cited as examples of what would not work, and, elsewhere, the 1 tonne limitation leads a correspondent to conclude that this would impose a lifestyle that would pre-date her own lifetime and that most people in the modern world just could not imagine. One UK doctor describes the obstacles he experienced in including considerations of how to save energy in plans to build a new practice.

Altogether, correspondents chipped in many good ideas, but it still looks like "too little, too late." It is obvious that individuals, however hard and focused their attempts, will not achieve enough critical mass to counteract the effects of climate change and that the problem needs to be tackled on a collective scale. How consoling, then, that one correspondent points out that, although global warming undeniably exists, every mass extinction in the fossil record was actually accompanied by global cooling.

Birte Twisselmann assistant editor (web) $B M J$

Competing interests: None declared.

1 Electronic responses. Fiona Godlee's carbon blog. bmj.com 2006. http://bmj.bmijournals.com/cgi/eletters/ 332/7554/DC1 (accessed 14 Jun 2006).

2 Electronic responses. What did you do about climate change Mum? bmj.com 2006. http://bmj. bmijournals.com/cgi/eletters/332/7554/0-f (accessed 14 Jun 2006).

3 Electronic responses. What health services could do about climate change. bmj.com 2006. http:// bmj.bmijournals.com/cgi/eletters/332/7554/1343 (accessed 14 Jun 2006).

4 Electronic responses. Healthy response to climate change. bmj.com 2006. http://bmj.bmijournals.com/cgi/eletters/ 332/7554/1385 (accessed 14 Jun 2006.)

**We have had a good response to our call for applications to join our carbon council. Please keep them coming (email: editor@bmj.com). The closing date is 30 June-Fiona Godlee.

\section{Indigenous hepatitis $\mathrm{E}$ virus infection in England and Wales}

EDITOR-Palmer et al undertook a qualitative risk assessment of the emerging zoonotic potential of porcine hepatitis $\mathrm{E}$ virus (HEV). ${ }^{1}$ They recommended enhanced surveillance of non-A, non-B, non-C hepatitis after noting that sporadic cases of HEV may be missed in humans as testing is not routine in the UK without a history of foreign travel.

We investigated cases of HEV in England and Wales to describe the epidemiology and study possible risk factors for the acquisition of indigenous infection. Between 1 January 2005 and 30 June 2005 the Health Protection Agency HEV reference laboratories confirmed 181 cases of acute hepatitis E, including five deaths in patients with underlying serious medical conditions. Travel to an endemic area was recorded for 69 cases, so further enquiries were made into the remaining 112 cases with an unknown travel history. 
Twenty five (14\%) patients had not travelled outside the United Kingdom in nine weeks before their illness and of these 20 $(80 \%)$ were male and the median age was 59 years (interquartile range 43 to 71.5 years). Ten of these cases were polymerase chain reaction positive, all but one were HEV genotype 3 (North American and European genotype). Twenty four of the 25 patients had nonSouth Asian names. On the basis of HEV genotype 3 and demographic information (age within interquartile range and nonSouth Asian name), an additional 23 patients for whom the travel history is unknown were likely to have acquired their infection in the UK. Twenty two non-travel associated case patients were interviewed by using a detailed trawling questionnaire. Despite the striking demographic finding that the majority of cases were middle aged to elderly white men, no common source, including contact with pigs or pig food products, has so far been identified by our study.

The total number of cases reported in the first six months of 2005 was three times that expected on the basis of routine voluntary surveillance, and the proportion of non-travel associated cases was much larger than that previously reported. ${ }^{2}$ With the evolving epidemiology of HEV in England and Wales, HEV should be considered as an aetiological agent of acute and fulminant hepatitis in patients reporting no travel history. We therefore need to raise awareness among health professionals of the requirement for further investigation of non-travel associated cases of non-A, non-B, non-C hepatitis and standardise laboratory and hospital referral procedures.

Hannah Lewis epidemiologist

hannah.lewis@hpa.org.uk

Dilys Morgan consultant epidemiologist

Samreen Ijaz clinical scientist

Health Protection Agency, Centre for Infections, London NW9 5EQ

Elizabeth Boxall clinical scientist

Health Protection Agency Heartlands Hospital, Birmingham B9 5SS

Competing interests: None declared.

1 Palmer S, Brown D, Morgan D. Early qualitative risk assessment of the emerging zoonotic potential of animal diseases. BMJ 2005;331:1256-60.

2 Ijaz S, Arnold E, Banks M, Bendall RP, Cramp ME, Cunningham R, et al. Non-travel-associated hepatitis $\mathrm{E}$ in England and Wales: demographic, clinical, and molecular epidemiological characteristics. I Infect Dis 2005;192: 1166-72.

\section{Health research funding}

Mental health research continues to be underfunded ...

EDITOR-The UK Clinical Research Collaboration's graph showing funding for research in 2004-5 by disease area compared with estimates of disability adjusted life year or DALY is misleading. ${ }^{1}$ DALYs for neurological disorders and mental health have been combined, suggesting that funding for the area approximately equates proportionally to them. If they are separated funding for mental health remains substantially lower than is warranted

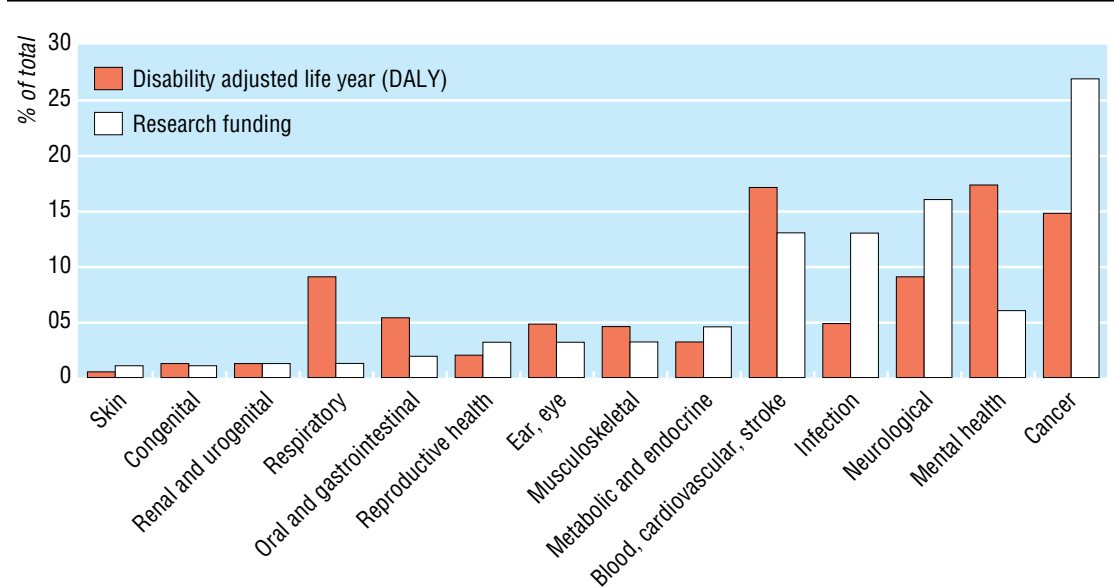

Funding for UK research in 2004-5 by disease area and disability adjusted life year (DALY)

by its impact on health and the priority given to it by the government (figure). Mental health research also receives very little funding from other sources-for example, charities and industry. As the overwhelming response to the MRC Brain Sciences Appeal showed last year, this is now an area where rapid expansion of research is possible and funding should now reflect it.

David Kingdon professor of mental health care delivery

University of Southampton, Royal South Hants Hospital, Southampton SO18 2PG

dgk@soton.ac.uk

Competing interests: DK applies for grants for mental health research.

\section{Mayor S. Report gives snapshot health research funding in the UK. BMJ 2006;332:1230. (27 May.)}

\section{... while injuries were ignored}

EDITOR-Mayor's commentary on the UK Clinical Research Collaboration's analysis of health research funding points to a few discrepancies between the level of research funding in disease areas and the health burden of those diseases. ${ }^{12}$ However, by far the biggest discrepancy was overlooked, probably because it was ignored and not reported by the collaboration.

Despite the research funding profile being broken down into 20 disease categories including injuries and accidents, the collaboration compared levels of funding with disease burden in only 12 categories excluding injuries and accidents. However, the data source used for calculating disease burden using disability adjusted life years (DALYs) clearly gives the DALYs for injuries. ${ }^{3}$

The results show that, although accidental injuries contribute $4.1 \%$ of UK DALYs and non-accidental injuries a further $2.5 \%$, only $0.3 \%$ of the health research funding analysed is spent in this area. This 22-fold discrepancy $(6.6 \%$ to $0.3 \%)$ is much higher than the next biggest discrepancy, the highlighted sixfold difference for respiratory disease. Given that there is almost no other charity or industry research funding in the area of injuries, unlike in other areas such as asthma and arthritis, the position is even bleaker.
This issue has been highlighted before, particularly by the BMA, ${ }^{4}$ and the anomaly should be rectified.

Jon P Nicholl director

Medical Care Research Unit, University of

Sheffield, Sheffield S1 4DA

j.nicholl@shef.ac.uk

Competing interests: None declared.

1 Mayor S. Report gives snapshot health research funding in the UK. BMJ 2006;332:1230. (27 May.)

2 UK Clinical Research Collaboration. UK health research analysis. London: UKCRC, 2006.

3 World Health Organization Burden of disease Project Death and DALY estimates for 2002 by cause for WHO member states (2002). www.who.int/entity/healthinfo/ statistics/bodgbd-deathdalyestimates.xls (accessed 8 Jun

4 BMA. Injury prevention. London: BMA, 2001

\section{It's difficult being green (as in vomit)}

EDITOR-Walker et al evaluated the colour of vomit in newborn infants, and the perception of health professionals on whether it constituted bile.

In our neonatal intensive care unit (and on the postnatal wards) we had noted that there was a wide variation in what was being called "bile." Feeds were withheld unnecessarily in some infants-particularly very small preterm infants, in whom some discoloration of their gastric aspirates is common-whereas in others they were continued when frank bile was apparent.

We therefore developed a local guideline on withholding feeds, and included a "colour chart" to help with identification of bile-stained vomit or gastric aspirates. ${ }^{2}$

Although the primary intention was to ensure that feeds were not withheld in the smallest infants, a secondary intention was to remind others that bilious vomiting requires a careful assessment of the infant and careful consideration of an intestinal obstruction (especially malrotation) as a potential aetiology.

However, when it came to labelling colours, it was a considerable challenge to name the colours we had chosen-one person's "forest" was another's "grass." It was not until we settled on the tried and true 
method of naming bodily secretions by their resemblance to food-for example, "mustard" and "spinach"-that we all knew what each of us meant.

Carl A Kuschel clinical director, newborn services CarlK@adhb.govt.nz

\section{Barbara Cormack dietitian}

Phil Morreau paediatric surgeon

Auckland District Health Board, Auckland 1001, New Zealand

Competing interests: None declared.

1 Walker GW, Neilson A, Young D, Raine PAM. Colour of bile vomiting in intestinal obstruction in the newbor questionnaire study. BMJ 2006;332:1363-5. (10 June.)

2 Kuschel C, Cormack B, Morreau P. Newborn Services clinical guideline. Available at: www.adhb.govt $\mathrm{nz} /$ newborn/Guidelines/Nutrition/WithholdingFeeds. htm\#Colour (accessed 16 Jun 2006)

\section{New antipsychotic agents are much awaited}

EDITOR-I agree with Ganguli and Strassnig that truly novel antipsychotic agents are needed. ${ }^{1}$ They talk about older antipsychotics not becoming obsolete in clinical practice, while the amount of research that is conducted solely into their efficacy is slim. We remain in the dark when it comes to comparing typical antipsychotics, individualising them to the needs of a patient. The evidence base is anecdotal. They are effective in clinical practice; every psychiatrist has a cohort of patients stabilised on them, followed up regularly and maintained similarly lest they should decompensate. However, the pharmaceutical industry pours funds into development of newer compounds or newer licences for existing "novel" antipsychotics, and the older ones fade into the background, serving mainly as adjuvant to the control of behavioural symptoms on the inpatient unit.

Safer avenues of antipsychotic prescription need to be explored, given that the metabolic syndrome, glucose metabolism abnormalities, and accelerated ageing have been documented with the newer agents and the UK Committee on Safety of Medicines has informed clinicians that risperidone and olanzapine should not be used to treat behavioural and psychological symptoms of dementia because of increased risk of strokes with both drugs and increased risk of mortality with olanzapine. ${ }^{2}$ Baldessarini et al concluded that moderate doses of chlorpromazine were most effective for acute symptom control, suggesting evidence of a biphasic or inverted U shaped curve for the dose-response relation. ${ }^{3}$ They and others have shown similar results for maintenance treatment. Higher doses merely increase side effects.

The trusted drugs have a role, provided that they can be supported with a better evidence base on their efficacy and side effects.

Arnob Chakraborti senior house officer

Dorothy Pattison Hospital, Walsall Primary Care Trust, Walsall WS2 9XH

ac97dmc@googlemail.com

Competing interests: None declared.
1 Ganguli R, Strassnig M. Are older antipsychotic drugs obsolete? BMJ 2006:332:1346-7. (10 June.)

MHRA New advice issued on riperidone and olanzapine. Press release 9 March 2004 .

Press release 9 March 2004. Baldessarini KJ, Cohen BM, Teicher MH. Significance of rearict

trent

\section{Gabapentin may cause reversible visual field constriction}

\section{Learning or inattention artefact a more} likely explanation

EDITOR-I was interested to read the account by Bekkelund et al of an apparent visual field constriction related to use of gabapentin. Unfortunately, the authors seem to have overlooked the most common cause of this type of visual field defect: artefact.

Automated testing will often give this pattern of "field defect" in subjects who have difficulty concentrating, have trouble following instructions, or are simply learning to do the test. Usually, this type of artefact is apparent from the reliability indices on the printout from the Humphrey Field Analyser. ${ }^{2}$ Unfortunately, these data were edited out of the field plots by Bekkelund et al, but this learning or inattention artefact can be present even if the reliability indices seem to be good. It is common for this type of field defect to appear variable and then resolve with repeated testing, as the subject learns how to carry out the test. A similar report, of reversibility of vigabatrin induced visual field defect is also most likely to represent learning or inattention artefact. ${ }^{3}$ Clinicians should be aware of the limitations of automated testing when screening for visual field defects.

Tom Eke consultant ophthalmologist

Norfolk and Norwich University Hospital, Norwich NR4 7UY

tom.eke@nnuh.nhs.uk

Competing interests: TE was first author of the original paper on vigabatrin and visual field defects (reference 1 in the paper by Bekkelund et al) and has received honorariums and trave expenses from the manufacturers of vigabatrin. He has been a paid adviser on medicolegal issues related to vigabatrin and visual fields.

1 Bekkelund SI, Lilleng H, Tonseth S. Gabapentin may cause reversible visual field constriction. BMJ 2006;332:1193. (20 May.)

2 Heijl A, Patella VM. Essential perimetry: the field analyzer primer. 3rd ed. Dublin, CA: Carl Zeiss Meditec, 2002.

3 Versino M, Veggiotti P. Reversibility of vigabatrin-induced visual-field defect. Lancet 1999;354:486.

\section{GABA transaminase inhibitors may cause} irreversible visual field loss

EDITOR-We have a few points to raise in relation to the case report of Bekkelund et al. ${ }^{1}$ Field loss with GABA transaminase inhibitors is a well recognised phenomenon, but most case series have shown that it is irreversible. The field loss seen in patients is normally (but not entirely) a binasal field loss-arcuate scotoma is very unusual.

Investigation of these patients with GDx VCC scanning laser polarimetry (Laser Diagnostic Technologies, San Diego, CA, USA) shows a loss of retinal nerve fibre layer, with the longer nerve fibres being affected primarily (hence the binasal appearance of the scotomata). The advent of this investigation is going to supersede regular perimetry investigations as it is non-invasive, quick, relatively easy to perform, and can be used in children and patients with learning difficulties-both groups highly represented in the population taking vigabatrin. The physical loss of nerve fibre layer is permanent and cannot be a transient effect.

The progression and improvement of the fields in the case report may be attributed to the learning curve of field testing-the more fields a patient performs the better they seem to become. Before any field test is analysed the reliability parameters must be detailed.

Jon M Durnian specialist registrar ophthalmology jon_durnian@hotmail.com

Louis G Clearkin consultant ophthalmologist Arrowe Park Hospital, Upton, Wirral CH49 5PE

Competing interests: None declared.

1 Bekkelund SI, Lilleng H, Tonseth S. Gabapentin may cause reversible visual field constriction. BMJ 2006;332:1193. (20 May.)

\section{Improving surveillance for Barrett's oesophagus}

\section{Better to be looked over than be} overlooked

EDITOR-The audit by Bampton et al highlights the practical problems encountered in the area of Barrett's oesophagus surveillance. ${ }^{1}$ Our retrospective audit of 441 patients with Barrett's oesophagus in a university teaching hospital setting showed an alarmingly low compliance rate of $8.6 \%{ }^{2}$ The main area of concern was that quadrantic biopsies were not taken in a large proportion of patients. Similar figures were seen in an audit in United States, where the compliance rates varied from $14 \%$ to $38 \%$ in a patient population from both teaching hospitals and community centres. ${ }^{3}$ As seen by Bampton et al, the prospective audit in our centre after guidelines were disseminated among endoscopists showed improved compliance only to $61 \%$. The main reasons for lack of compliance continues to be the lack of dedicated endoscopy lists with extended time

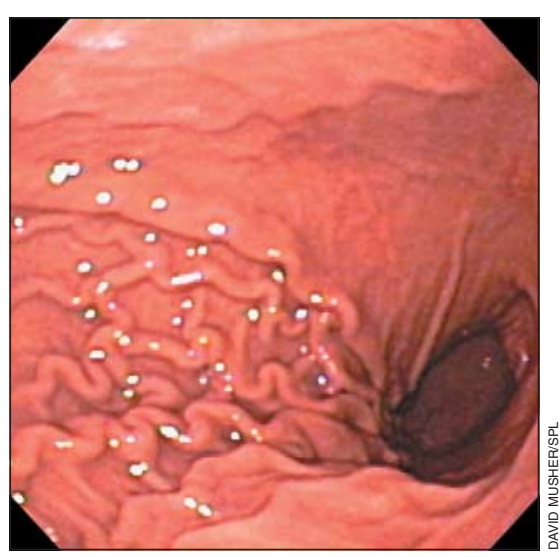


allocation and the ongoing debate between believers and non-believers of a surveillance strategy in Barrett's.

A recent United Kingdom audit drew similar conclusions. ${ }^{4}$ Using a dedicated practitioner to flag up patients with Barrett's oesophagus, in conjunction with an adequate mechanism to evaluate usefulness of surveillance in individual patients as shown by the authors, seems to be the way forward. Although the cost implications of this approach are to be fully evaluated in the study, we agree that the costs may be offset by the potential savings from the reduction in the number of endoscopies done at inappropriate intervals. The value of chromoendoscopy and magnifying endoscopy in Barrett's oesophagus is still evolving. For the moment four quadrant biopsies remain key to a useful surveillance programme. The endoscopy governance meetings should focus on the much needed attention to the quality of Barrett's surveillance in individual centres.

Shaji Sebastian consultant gastroenterologist

Hull Royal Infirmary, Hull HU3 2JZ

shaji.sebastian@hey.nhs.uk

\section{Colm O'Morain head}

Department of Gastroenterology, Adelaide and Meath Hospital, Dublin 24, Republic of Ireland

Competing interests: Part of the data presented and published as an abstract at the UEGW 2004.

1 Bampton PA, Schloithe A, Bull J, Fraser RJ, Padbury RTA, Watson DI. Improving surveillance for Barrett's oesophagus. BMJ 2006;332:1320-3. (3 June.)

Sebastian S, Qasim A, McLoughlin R, Rathore O, Crotty P, et al. An audit of the biopsy protocol for Barrett's oesophagus-need to improve compliance to guidelines. Endoscopy 2004:36:A254

3 Chand N, Miller C, Cassara J, Ruffin K, Cattau EL et al Barrett's surveillance per the ACG guidelines, do we really do what they say? Am J Gastroenterol 2003;98:S20

4 Mandal A, Plyford RJ, Wicks C. Current practice in surveillance strategy for patients with Barrett's oesophagus in the UK. Aliment Pharmacol Ther 2003;17:1319-24.

\section{AspECT and BOSS trials provide an evidence base}

EDITOR-We read with interest the quality improvement report for improving surveillance for Barrett's oesophagus by Bampton et al. ${ }^{1}$ Improving adherence to guidelines that are themselves lacking a sufficient evidence base may not actually improve hard clinical outcomes such as all causes of mortality or even cancer progression.

The major problem with a surveillance only approach is that only an estimated $5-10 \%$ of patients with Barrett's oesophagus will benefit as the rest are either not referred for endoscopy or default the surveillance programme. ${ }^{2}$ The real value of surveillance needs to be tested in a randomised trial so that all confounding issues associated with surveillance can be independently assessed. The Barrett's oesophagus surveillance study (BOSS) aims to randomise 2500 patients with proved Barrett's oesophagus to either surveillance endoscopy as recommended in the guidelines recommended by Bampton et al and no surveillance for patients. ${ }^{13}$

In this trial, full written informed consent of all the relevant issues will take place and, although the trial is about to start, we will be able to address whether patients in the non-surveillance arms will violate the
BOSS protocol by withdrawal from the study owing to anxiety over existing and new "reflux" symptoms. There could be other outcomes, however, as we already have provisional evidence to indicate that chemoprevention of Barrett's oesophagus may decrease cancer incidence by up to $45 \%{ }^{3} \mathrm{It}$ is possible, therefore, that once cancer incidence is stratified by aspirin use in the surveillance and non-surveillance arms the value of surveillance will be modest and perhaps even neutral when taking into account other issues such as endoscopic and multiple biopsy induced mortality, morbidity, and anxiety. The role of chemoprevention is itself already being tested in another large randomised study involving 5000 patients with Barrett's oesophagus, the aspirin esomeprazole chemoprevention trial (AspECT).

We wonder whether in the fullness of time resources may perhaps be proved to be better spent in mass chemoprevention for patients with reflux disease ( $>35$ years) for 10 or more years.

Janusz Jankowski chief investigator, AspECT trial Department of Clinical Pharmacology, University of Oxford, Oxford OX2 6HE

janusz.jankowski@clinical-pharmacology.oxford.ac.uk

Hugh Barr chief investigator, BOSS trial

Department of Surgery, Gloucestershire Royal

Hospital, Gloucester GL1 3NN

Competing interests: None declared.

1 Bampton PA, Schloithe A, Bull J, Fraser RJ, Padbury RTA, Watson DI. Improving surveillance for Barrett's oesophagus. BMJ 2005;332:1390-3. (3 June.)

2 JankowskiJ. Hawk E. A methodological analysis of chemoJankowskij, Hawk E. A methodological analysis of chemoGrevention in the Gastro $2006: 3 ; 101-11$.

Jankowski J, Moayedi P. Aspirin as chemoprevention for Jankowski J, Moayyedi P. Aspirin as chemoprevention for Barrett's esophagus: a large RCT underway in the UK Inst 2004;96:885-7.

\section{Switching statins}

\section{Cost of simvastatin is overestimated}

EDITOR-Although the savings identified by Moon and Bogle look impressive, ${ }^{1}$ and the price of simvastatin may look cheap; the authors have overstated the cost of simvastatin to the NHS by a factor of 4 , and the future cost, probably by a factor of 8 and maybe 40 .

The market price for simvastatin $10 \mathrm{mg}$ is $29 \mathrm{p}$ per pack, $20 \mathrm{mg}$ is $39 \mathrm{p} /$ pack, and 40 $\mathrm{mg}$ is $96 \mathrm{p} /$ pack. $^{2}$ The difference with the tariff price ( $£ 1.81, £ 2.34$, and $\left.£ 4.23^{3}\right)$ is pharmacy profit. Profit on category $M$ products helps fund pharmaceutical services. Increased prescribing of simvastatin will not result in increased pharmacy profits as the price of this and other category $\mathrm{M}$ products is adjusted quarterly to maintain a predetermined overall level of profit. The real cost to the NHS hence is the market cost, not the tariff price.

Simvastatin $40 \mathrm{mg}$ has been in comparative short supply in the market owing to its popularity after the heart protection study and recent reductions in tariff price that have now made it an attractive switch for cash strapped primary care trusts. Its longer term price should be twice the price

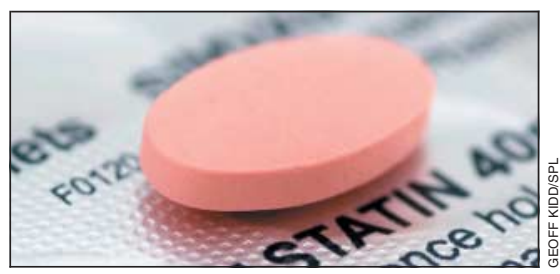

difference between the $10 \mathrm{mg}$ and $20 \mathrm{mg}$ tablets above the market price of the $20 \mathrm{mg}$ tablet; or about 56p/pack. Given the volume, this is probably still an overestimate and a price in line with bendroflumethiazide (2.5 mg, 9p/pack) or atenolol $(50 \mathrm{mg}$, $9 \mathrm{p} /$ pack) is likely. ${ }^{2}$

The National Institute for Health and Clinical Excellence (NICE) has also failed to recognise this in its cost analysis. NICE also underestimates the savings in hospital costs, which are clearly out of line with the savings seen in the economic analysis of the heart protection study. ${ }^{4}$

John S Ashcroft general practitioner

Old Station Surgery, Ilkeston, Derbyshire DE7 8ES jsashcroft@nhs.net

Competing interests: None declared.

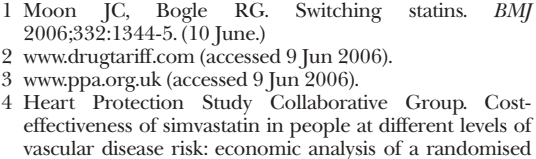

\section{NICE tool overestimates benefits of statins}

Editor-Moon and Bogle should be supported in their call to move from branded to generic statins. ${ }^{1}$ However, by using the costing tool of the National Institute for Health and Clinical Excellence (NICE), ${ }^{2}$ they have probably overestimated the benefits of statins.

The 10 year risk thresholds for cardiovascular disease for starting a statin in primary prevention have recently been reduced from $40 \%$ to $20 \% .^{23}$ The NICE tool models the impact of this change by adding together the effect of statins on a range of cardiovascular events by using trial findings for fatal and non-fatal myocardial infarction, angina, transient ischaemic attack, and stroke. I have tested this approach by comparing the results of the NICE tool with a new analysis of Scottish health survey 1998 data. $^{4}$

When population figures for Lothian, Scotland (population 779 000) are used, the NICE tool estimates that 23648 additional people would receive statins with the revised cardiovascular risk thresholds and that as a result 364 events would be prevented per year. The Scottish health survey's analysis used data from 2760 participants aged 40-74 years without evidence of cardiovascular disease or diabetes. The mean cardiovascular risk derived from Framingham equations for participants in the survey newly eligible for a statin when using the revised risk thresholds was estimated at $2.65 \%$ per year. Using this estimate, without statins the group of 23648 patients identified by the NICE tool would experience 627 cardiovascular events per year. 
On the basis of these findings, using the NICE tool is equivalent to assuming that statins produce a $58 \%$ relative risk reduction in cardiovascular events. In contrast, a recent meta-analysis estimated that the relative risk reduction in cardiovascular events with statins was 21\% (per mmol/l reduction in LDL cholesterol), and even this is likely to have been an overestimate as the meta-analysis included some high risk patients. ${ }^{5}$ NICE should reassess its costing tool for statins.

D Graham Mackenzie specialist registrar in public health

Public Health Department, NHS Fife, Windygates, Fife KY8 5RG

gm@nhs.net

Competing interests: None declared.

1 Moon JC, Bogle RG. Switching statins. BMJ 2006:332:1344-5. (10 June)

2 TA94 Cardiovascular disease-statins: analysis of cost impact. www.nice.org.uk/page.aspx?o $=289620$ (accessed impact. www.n.

3 Wood D, Wray R, Poulter N, Williams, Kirby M, Patel V, et al. JBS 2: Joint British Societies' guidelines on prevention of cardiovascular disease in clinical practice. Heart of cardiovas

4 Scottish health survey 1998. Volume 1. www.show.scot.nhs.uk/sehd/scottishhealthsurvey/sh8-00. www.show.scot.nhs.uk/seh

5 Cholesterol Treatment Trialists' Collaborators. Efficacy Cholesterol Treatment Trialists Collaborators. Efficacy and safety of cholesterol-lowering treatment: prospective randomised trials of statins. Lancet 2005;36:1267-78.

\section{How to do it without tears and to benefit} the NHS

EDITOR-Moon and Bogle discuss how switching to generic simvastatin could save money for the NHS in England. ${ }^{1}$ The All Wales Medicines Strategy Group (AWMSG) was established in 2002 to advise the minister of health of the Wales Assembly on promoting safe and cost effective prescribing. The group considers that the promotion of generic simvastatin as the most cost effective statin of choice will greatly benefit NHS Wales. This is based on robust evidence.

General practitioners in Wales are advised that generic simvastatin should be the most cost effective statin of choice for new patients receiving statin treatment. Switching was not actively promoted as such. To help local health boards to balance their budgets, a subgroup of the AWMSG was tasked to develop the all Wales prescribing incentive scheme.

The Newport board has included generic simvastatin as an indicator in its prescribing incentive scheme in the past three years. No prescribing policy can be implemented effectively without the goodwill of general practitioners, and they must be on board. In Newport, the health board pharmacist and the general practitioner prescribing lead will visit practices to discuss the evidence that supports the switch. The health board prescribing support team can provide practices with pharmacy technicians to facilitate the switch. Currently, in Newport generic simvastatin is more than $65 \%$ of all statins prescribed and is still rising. It has saved $£ 100000$ s so far.

The evidence is that the statins do not differ in their effectiveness in lowering the morbidity and mortality in secondary prevention. ${ }^{2}$ Effective dosage of statin is the key-simvastatin $40 \mathrm{mg}$ daily. Clinicians will have to appraise the evidence critically to decide whether it is more important for us to base our day to day practice on patients' outcome or on biochemical targets.

Thomas Lau general practitioner

Lliswerry Medical Centre, Newport, Gwent NP20 5EB

lmclau@hotmail.com

Competing interests: TL is general practitioner prescribing lead, Newport Local Health Board, and a member and formerly chair of the All Wales Prescribing Group.

1 Moon JC, Bogle RG. Switching statins. $B M J$ 2006;332:1344-5. (10 June.)

2 Duerden MG. Switching statins works with "an adequate dose" but not "target-chasing." Electronic response to: Switching statins. http://bmj.bmijournals.com/cgi/ eletters $/ 332 / 7554 / 1344$ ? $\mathrm{ck}=$ nck $\# 135339$

\section{Smoking, Helicobacter pylori, and periodontitis}

EDITOR-BMJ Updates summarises a fascinating study. ${ }^{12}$ It gives further support to the view that the reservoir of Helicobacter pylori in dental plaque on teeth cannot be removed by systemic antimicrobials and is an important potential source of reinfection. ${ }^{3}$ The link between smoking and periodontitis has become well established over the past 20 years. In addition to exacerbating periodontitis, smoking also interferes with the treatment outcome. The magnitude of the problem was assessed in a recent paper based on NHANES III data, in which the authors found that smokers in the 30-75 age group were six times more likely to have advanced periodontitis. ${ }^{4}$

In patients who smoke and whose gums have been damaged by periodontitis, a reservoir of dental plaque exists not only above the gums, but also below the gums in periodontal pockets. As plaque is a biofilm, organisms in it are protected from systemic antimicrobials and must be removed mechanically by instrumentation if they are to be removed at all. The potential for reinfection of the stomach by $H$ pylori is obvious. Large clinical trials of the effect of thorough periodontal treatment on this problem are long overdue.

Trevor L P Watts honorary consultant in periodontology

King's College London Dental Institute at Guy's, King's, and St Thomas' Hospitals, London SE1 9RT trevor.watts@kcl.ac.uk

Competing interests: None declared

1 BMJ updates. It's harder to eradicate Helicobacter pylori in smokers. BMJ 2006;332. (10 June.)

2 Suzuki T, Matsuo K, Ito H, Sawaki A, Hirose K, Wakai K, et al. Smoking increases the treatment failure for Helicobacter pylori eradication. Am J Med 2006;119: 217-24

3 Watts T. Dental plaque is a potential reservoir of Helicobacter pylori. BMJ 2002; 324: 614-5.

4 Hujoel PP, del Aguila MA, DeRouen TA, Bergstrom J. A hidden periodontitis epidemic during the 20th century? Community Dent Oral Epidemiol 2003;31:1-6.

\section{Injury from lightning strike while using mobile phone}

EDITOR-We report the case of a 15 year old girl who was witnessed being struck by lightning while using her mobile phone in a large park in London during stormy weather. The girl has no recollection of events because she had an asystolic cardiac arrest.

She was successfully resuscitated, but one year later she was a wheelchair user with complex physical, cognitive, and emotional problems, as well as a persistent perforation of the left tympanic membrane with associated conductive hearing loss on the side she was holding the mobile phone.

If someone is struck by lightning the high resistance of human skin results in lightning being conducted over the skin without entering the body; this is known as flashover. ${ }^{1}$ This phenomenon has a low mortality. Conductive materials in direct contact with skin such as liquids or metallic objects disrupt the flashover and result in internal injury with greater morbidity and mortality.

To our knowledge, no similar cases have been reported in the medical literature. We found three cases reported in newspapers in China, Korea, and Malaysia. ${ }^{2-4}$ All these events resulted in death after the people were struck by lightning while using their mobile phones outdoors during storms.

This rare phenomenon is a public health issue, and education is necessary to highlight the risk of using mobile phones outdoors during stormy weather to prevent future fatal consequences from lightning strike injuries related to mobile phones.

The Australian Lightning Protection Standard recommends that metallic objects, including cordless or mobile phones, should not be used (or carried) outdoors during a thunderstorm. ${ }^{5}$ We could not find any advice from British telecommunication companies.

Swinda Esprit senior house officer in

otorhinolaryngology

swinda@runbox.com

Prasad Kothari specialist registrar in

otorhinolaryngology

Ram Dhillon consultant in otorhinolaryngology

Northwick Park Hospital, Middlesex HA1 3UJ

Competing interests: None declared.

1 Mason AD, Crockett RK. When lightning strikes ... A case report and review of the literature. Int Paediatr 2000;15(3). 2 Cell phone could have led to death of tourist on Great Wall. China View 2004 Aug 15. http:// Wall. China View 2004 Aug
news.xinhuanet.com/english/2005-08/15/ content 3355652.htm (accessed 14 Jun 2006).

3 Ah-young C. Man talking on cell phone dies from lightning injury. Korea Times 2004 March 8:16.42.

4 Man using cell phone killed by lightning. Singapore Strait Times 1999 Sept $11: 40$.

Times 1999 Sept 11:40. 5 Australian Lightning Protection Standard AS/170, National Lightning Safety Institute (2004). See: Australian Government Bureau of Meteorology. The WA Stormspotter. Vol 8, No 1, 20 December 2004. Storm safety: wa/sevwx/spdec04.shtml (accessed 14 Jun 2006).

\section{bmj.com}

We select the letters for these pages from the rapid responses posted on bmj.com favouring those received within five days of publication of the article to which they refer.

Letters are thus an early selection of rapid responses on a particular topic. Readers should consult the website for the full list of responses and any authors' replies, which usually arrive after our selection. 